\title{
The Function of $\mathrm{TiO}_{2}$ with Respect to Sensitizer Stability in Nanocrystalline Dye Solar Cells
}

\author{
A. Barkschat, T. Moehl, B. Macht, and H. Tributsch \\ Department Solare Energetik, Hahn-Meitner-Institut, 14109 Berlin, Germany \\ Correspondence should be addressed to H. Tributsch, tributsch@hmi.de
}

Received 25 October 2007; Accepted 13 December 2007

Recommended by M. Sabry Abdel-Mottaleb

\begin{abstract}
Dyes of characteristically different composition have been tested with respect to long-term stability in operating standardized dye sensitized cells during a time period of up to 3600 hours. Selective solar illumination, the use of graded filters, and imaging of photocurrents revealed that degradation is linked to the density of photocurrent passed. Photoelectrochemical degradation was observed with all sensitizers investigated. Sensitization was less efficient and sensitizers were less photostable with nanostructured $\mathrm{ZnO}$ compared to nanostructured $\mathrm{TiO}_{2}$. The best performance was confirmed for cis- $\mathrm{Ru}^{\mathrm{II}}\left(\mathrm{dcbpyH}_{2}\right)_{2}\left(\mathrm{NCS}_{2}\right.$ on TiO ${ }_{2}$. However, it was 7-10 times less stable under other identical conditions on $\mathrm{ZnO}$. Stability is favored by carboxylate anchoring and metal-centred electron transfer. In presence of $\mathrm{TiO}_{2}$, it is enhanced by formation of a stabilizing charge-transfer complex between oxidized Ru dye and back-bonding interfacial $\mathrm{Ti}^{3+}$ states. This is considered to be the main reason for the ongoing use of expensive Ru complexes in combination with $\mathrm{TiO}_{2}$. The local surface chemistry of the nanocrystalline $\mathrm{TiO}_{2}$ turned out to be a crucial factor for sensitizer stability and requires further investigation.
\end{abstract}

Copyright (c) 2008 A. Barkschat et al. This is an open access article distributed under the Creative Commons Attribution License, which permits unrestricted use, distribution, and reproduction in any medium, provided the original work is properly cited.

\section{INTRODUCTION}

The sensitization of emulsions of semiconductor particles has played a major role in the development of photography $[1,2]$. Photoelectrochemical studies on the mechanisms of spectral sensitization of semiconductors were performed in the late sixties [3-5]. Shortly thereafter, it was proposed to use dye sensitization to drive a new kind of solar cell [6]. The sensitizing Chlorophyll molecules were extracted from spinach to demonstrate solar energy conversion in analogy to primary photosynthesis $[5,6]$ (this, and not, as later claimed [7] the so called Grätzel cell, proposed 20 years later, was the first demonstration of bioanalogue solar energy conversion using dye molecules). Although, in the subsequent years, much scientific information on the sensitization process became available and reasonably efficient dye sensitized solar cells were demonstrated [8-14] on the basis of sintered oxide ceramics, it became more and more evident that the stability of organic sensitizers in such cells was a major problem. Nevertheless, in 1980, Matsumura et al. showed that on the basis of zinc oxide ceramics made intentionally porous with addition of aluminium, an efficiency for conversion of light into electrical energy of $2.5 \%$ could be achieved (illumination occurred only in the absorption region of the dye) [14]. Up to that time, dyes from very different groups of chemicals and many different large gap semiconductors had been tested for the sensitization phenomenon. In 1980, Dare-Edwards et al. tested Ru-based dyes by attaching them with two ester linkages to $\mathrm{TiO}_{2}[15]$. At that time, with respect to efficiency, no peculiar advantage of attached $\mathrm{Ru}(\text { bipy })_{2}$ (bpca) on a $\mathrm{TiO}_{2}$ large gap semiconductor was observed. This was probably due to the specific experimental conditions involved. Some deterioration of current efficiency after many hours of illumination of the sensitized electrode was specifically mentioned. Interestingly, it was a very similar system which became the focus of attention 10 years later when highefficiency, long-term stable nanocrystalline dye sensitized solar cells were proposed [16]. They used nanostructured $\mathrm{TiO}_{2}$ material sensitized via chemically attached Ru-based dyes in combination with an $\mathrm{I}^{-} / \mathrm{I}^{3-}$ redox electrolyte. With such systems, solar energy conversion efficiencies of $7-$ $10 \%$ were demonstrated with at least several $\mathrm{cm}^{2}$ large cells (tiny cells reached 11-12\%). A reasonable short-term stability was obvious when the cells were tightly sealed but a long-term stability of 20 years was claimed on the 
basis of rather complicated experimental and theoretical arguments [17]. Involvement of the excited Ru-sensitizer in photochemistry was excluded due to a fast (femtosecond) injection rate observed for the electron into $\mathrm{TiO}_{2}$ [18].

A fast regeneration of the oxidized Ru-sensitizer, on the other hand, was deduced from the presence of a high $(0.5 \mathrm{M})$ concentration of iodide in the electrolyte. Regeneration rates sufficient for stabilization of solar cells for over $10^{8}$ cycles corresponding to 20 years lifetime were calculated [17]. In the course of intensive research which followed in the nineties, complications with respect to electrolyte chemistry, photochemistry, purity of sensitizers, as well as with respect to sealing and iodine chemistry were noted [19]. The best performing cells saw their sensitizer change from a three nuclear Ru-complex [16] to the mononuclear cis$\mathrm{Ru}^{\mathrm{II}}\left(\mathrm{dcbpyH}_{2}\right)_{2}(\mathrm{NCS})_{2}$ complex (here called N3) and the electrolyte solutions were replaced by less volatile and more stable ones. But after 15 years of research on Ru-based dye solar cells, and after efforts by many groups, reasonably stable dye solar cells have still not found their way into production. In fact, several companies have failed to produce reasonably stable commercial cells, with larger panels still degrading too fast (e.g., on the main building of CSIRO-Energy in Newcastle, Australia).

Since long-term stability of dye sensitized cells is a crucial issue for economic feasibility, long-term studies of dye sensitized cells have been initiated in increasing numbers [20-27] to take advantage of the high energyconversion efficiency observed [28, 29]. However, a major problem turned out to be the sensitivity of the cells towards electrolyte loss via evaporation and the instability of the electrolyte. The chance of a dye sensitized solar cell to break down because of secondary phenomena not related to photochemical stability was very high. To overcome this problem, photocurrent imaging techniques were applied to visualize the effect of selective illumination of dye sensitized solar cells [30]. Only part of a dye sensitized solar cell was illuminated through a mask with simulated solar light (sulphur lamp) and the development of photocurrents were followed over a longer period of time by measuring spatially resolved images of the photocurrent. In these experiments, a $\mathrm{He} / \mathrm{Ne}$-laser spot was used for scanned illumination. In this way, clear differences between illuminated and nonilluminated areas could be observed [19]. This observation confirmed previous experiments with total reflection FTIRstudies performed on working dye sensitized solar cells. They indicated photo-induced generation of oxidation products of the Ru-sensitizer [31]. Significant quantitative differences between the performances of dye sensitized solar cells from different groups were observed. However, they behaved in a similar way qualitatively with respect to photo-induced degradation relative to stability in nonilluminated areas. A theoretical analysis of these preliminary studies indicated that the branching ratio, the ratio of regeneration rate of the oxidized sensitizer to the rate of product formation, is a crucial factor for stability of dye sensitized solar cells. It was estimated that it may be one order of magnitude lower than required for 20 years stability [32].

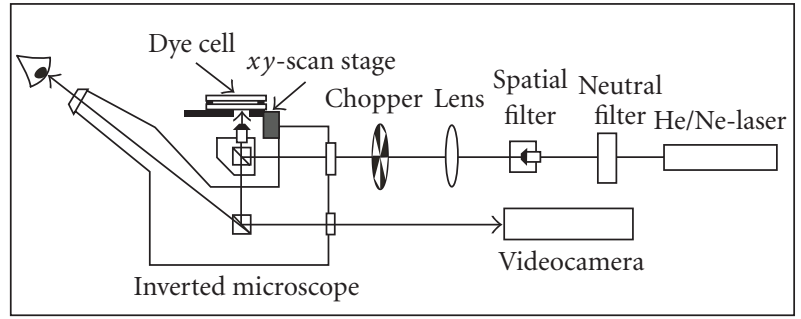

FIGURE 1: Scheme of the photoelectrochemical set up employing an optical scanning microscope (SMSC).

Some publications related the problem of dye cell degradation to the presence of water in the electrolyte [33] and other influences of the electrolyte $[17,31,34]$ to higher temperatures [35] and to UV-light incidence [35]. In a more recent paper, the degradation mechanisms in a dyesensitized solar cell were further investigated using UV/VISand IR-spectroscopy [36]. These results indicate a loss of the isothiocyanato-ligand of the $\mathrm{TiO}_{2}$-adsorbed dye in the presence of air, at higher temperature or in the presence of water in the electrolyte. This effect is accelerated by illumination. It was found that this leads to a decreased, blueshifted N3-dye absorption [36].

It is therefore necessary to investigate the problem of stability further, especially with respect to the origin of dye degradation. The question should specifically be answered is why, after so many years of intensive research on nanostructured dye solar cells, $\mathrm{TiO}_{2}$ and expensive $\mathrm{Ru}$-based sensitizers remained the by far preferred components of dye solar cells.

The aim of the present contribution is first to investigate different dyes, besides of the mainly used Ru-complex (N3), to study chemical preconditions for improved stability and, further, to find out whether the excited or the oxidized sensitizer is a key problem in inducing photochemical sidereactions. A key question will be the role which $\mathrm{TiO}_{2}$ and its surface chemistry play for sensitizer photodegradation. For this reason, $\mathrm{ZnO}$ will be studied as a substrate in parallel. It should be investigated to what extent the chemical quality and surface morphology of nano- $\mathrm{TiO}_{2}$ do have an influence on the survival of oxidized sensitizer molecules.

Photo-induced degradation, which is addressed here, is just one of several problems which can lead to degradation of dye sensitized cells. They have been discussed in a parallel publication [19] and include irreversible changes of the redox electrolyte, Li insertion into the oxide, loss of electrolyte through evaporation, and contamination from the atmosphere through the sealing material.

\section{EXPERIMENTAL}

The experimental strategy of this project consisted in fabrication of standard nanocrystalline dye sensitized solar cells like those now produced in many laboratories $[19,37,38]$. The cells were operated with 6 different sensitizers, which were selected as the most efficient from a larger number of dyes previously used. Both, cells made of nanocrystalline $\mathrm{ZnO}$ and 
$\mathrm{TiO}_{2}$ were compared, and the time-dependent performance of dye sensitized cells investigated by observing their photoelectrochemical performance and studying space resolved photocurrent images in order to distinguish the performance of illuminated and nonilluminated areas.

While screening a larger number of dyes (e.g., Ni-phtalocyanine, fluoresceine, rhodamine B, methylene blue, bromothymol blue, zinkone) for their function in standardized nanocrystalline dye sensitized cells, the work concentrated on the 6 best performing complexes. They were:

(i) bis(tetrabutylammonium) cis-bis(isothiocyanato)bis (2,2' -bi-pyridine-4-carboxylic acid, 4'-carboxylate) ruthenium(II) or cis- $\mathrm{Ru}^{\mathrm{II}}\left(\mathrm{dcbpyH}_{2}\right)_{2}(\mathrm{NCS})_{2}$, called N3 or Ru535 (obtained from Solaronics Inc., Aubonne, Switzerland),

(ii) porphyrine,

(iii) pyrogallol red,

(iv) sodium salt of copper-chlorophylline,

(v) di-(2,2' -dipyridylmethylene) $\left[\left(2,2^{\prime}\right.\right.$-dipyridylmethylene) malonato]ruthenium(II)dihexafluorophosphate $\cdot 2 \mathrm{HCL}$,

(vi) di-(2,2' -dipyridyl) $\left[\left(2,2^{\prime}\right.\right.$-dipyridylmethylene $)$ nomooctadecyl malonato]ruthenium(II).

With the exception of porphyrine when chloroform was used, the dyes were dissolved in ethanol to give $0.3 \mathrm{mM}$ stock solutions which were then applied to the nanocrystalline oxides.

\subsection{Dye sensitized cells}

Standard dye sensitized solar cells were prepared as described in the literature [19] and $\mathrm{TiO}_{2}$-layers were prepared by hydrolysis of $\mathrm{Ti}(\mathrm{IV})$ isopropylate $[39,40]$.

For the preparation of $\mathrm{TiO}_{2}$ layers, $1 \mathrm{~mL} 65 \%-\mathrm{HNO}_{3}$ was added to $120 \mathrm{~mL}$ of distilled water, and, for the next 45 minutes, a solution of $10 \mathrm{~mL} \mathrm{Ti}(\mathrm{IV})$ isopropylate in $10 \mathrm{~mL}$ isopropanol was added under constant stirring in an argon atmosphere. A white colloidal precipitation was formed, and the isopropanol was removed by distillation. When the solvent left was only water, the suspension was kept under reflux for 8 hours. The suspension was then heated to $230^{\circ} \mathrm{C}$ while being stirred in an autoclave for 12 hours. After removing the water by vacuum distillation, $40 \%$ polyethylenglycol 20000 (40\% relative to the content of $\mathrm{TiO}_{2}$ (11-20\%)) was added. This mixture was then applied onto the glass by pulling a glass rod over the surface. The thickness of the layer was kept constant by the use of a mask, which was fixed on the glass. The thickness of the $\mathrm{TiO}_{2}$ nanolayer was adjusted to $5 \mu \mathrm{m}$, which is smaller than the optimum for high efficiency $(10-15 \mu \mathrm{m})$ but adequate for $2-4 \%$ efficient experimental cells (excess dye should not be acting as a buffer). After drying for 15 minutes, the layers were tempered at $450^{\circ} \mathrm{C}$ for 30 minutes (cells of Figures 3(b), 3(c), 4(b), $6,7)$.

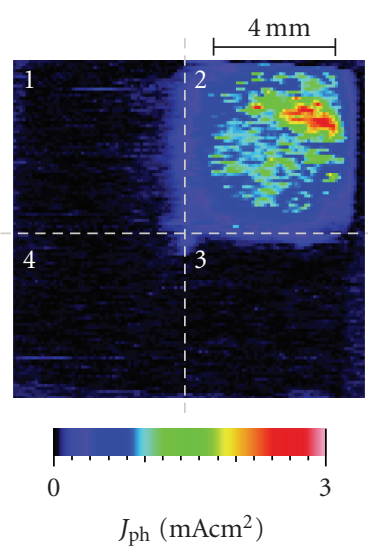

(a)

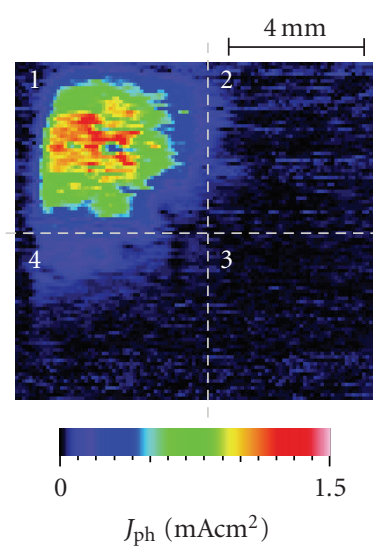

(b)
Figure 2: Photocurrent images of dye sensitized solar cells (nanocrystalline zinc oxide) subdivided into four sections for combinatorial testing (clock-wise from top left): (a) neutral red, N3-dye, rhodamine B, methylene blue; (b) N3-dye, neutral red, methylene blue, bromothymol blue. It is seen that only the N3 dye shows significant sensitization.

For ZnO-layers, commercial powders (Alfa, Aldrich) were used to prepare a suspension with the addition of acetyl acetone and water $(1: 10)$ and Triton X100 as a detergent.

The suspensions were again applied to the FTO-glass by pulling a glass rod over a mask, which was fixed on the glass. Afterwards, the samples were tempered at $450^{\circ} \mathrm{C}$ for 30 minutes (cells of Figures 2(a), 2(b), 3(a)).

Additionally, commercially available nanocrystalline $\mathrm{TiO}_{2}$-layers from the Institute for Applied Photovoltaics, Gelsenkirchen (INAP) were used. (cells of Figures 4(a), 4(c), $4(\mathrm{~d}), 8)$.

After tempering, the layers were dipped while still hot (approx. $80^{\circ} \mathrm{C}$ ) into a $0.2 \mathrm{mM}$ or $0.3 \mathrm{mM}$ solution of the dye. The second glass with the platinum back contact was fixed above the layer and the cells were sealed with Surlyn 1702 (DuPont). The whole cell was then put into electrolyte solution in an exsiccator. When vacuum was applied, the cell is filled with electrolyte. The electrolyte contained $0.5 \mathrm{M} \mathrm{LiI}$, $50 \mathrm{mM} \mathrm{I}_{2}$ and $0.2 \mathrm{M}$ tert.-butylpyridine in acetonitrile.

\subsection{Measurements}

Dye sensitized solar cells were characterized by photocurrent voltage measurements before exposing them to solar simulated light (sulphur lamp) under short-circuit conditions. A scanning laser spot technique was used to produce images of photocurrents as described in Chaparro et al. [41]. The scanning microscope for semiconductor characterization (SMSC) (see Figure 1) is basically an inverted microscope provided with an $x-y$ scan-stage. The laser spot was focussed by the microscope lens onto the dye sensitized solar cell, which was connected to a lock-in amplifier. The maximum spatial resolution of the used SMSC build up at HMI Berlin is $1 \mu \mathrm{m}$ with a laser spot of $2 \mu \mathrm{m}$ in diameter. In these experiments, a $\mathrm{He} / \mathrm{Ne}$-laser was used for illumination, 
the light intensity was adjusted to $100 \mathrm{mWcm}^{-2}$. In order to study photodegradation, only well-defined surface areas (using masks) of the dye sensitized cell were illuminated with simulated solar light (solar simulator with sulphur lamp). The photocurrent images were recorded at intervals to investigate the development of photodegradation.

\section{RESULTS}

Because quantitative reproducibility of dye sensitized cells turned out to be difficult (efficiency, electrolyte stability, durability of sealing, and long-term behavior varied from cell to cell) combinatorial approaches to dye sensitized properties of different compounds seemed to be appropriate. Figure 2 shows the photocurrent images of two dye sensitized cells, each of which has been separated into four sections dyed with different sensitizers. Three of the sensitizing substances (the Ru-complex N3, neutral red and methylene blue) were identical in order to test the reproducibility. The additional sensitizers were rhodamine $B$ in Figure 2(a) and bromothymol blue in Figure 2(b). As seen in Figures 2(a) and 2(b), only the Ru-complex N3 shows significant sensitized properties in the presence of the same iodide/triiodide-acetonitrile electrolyte. A larger number of potential candidates for sensitized were tested (e.g., Ni-phtalocyanine, fluoresceine, rhodamine B, methylene blue, bromothymol blue, zinkone) but only five additional compounds listed in the experimental section proved to be reasonably efficient for long-term testing. Among these were two additional Ru-complexes and the compounds porphyrine, pyrogallol red, and copper chlorophylline. Other compounds, such as rhodamine B or methylene blue, which had been demonstrated to sensitize $\mathrm{ZnO}$ reasonably well under different conditions, turned out not to be sufficiently effective in a nanocrystalline environment in the presence of an iodide/triiodide electrolyte in acetonitrile.

The six sensitizers mentioned were tested under comparable conditions in solar cells which had a nanocrystalline oxide layer of $4 \mu \mathrm{m}$ only. This is significantly smaller than in high-efficiency dye sensitized cells $(8-16 \mu \mathrm{m})$ so that the solar cell efficiency reached was correspondingly smaller. In the case of the N3 Ru-complex, the solar cell efficiency reached was between 2 and 3\%. The same sensitized cell with $\mathrm{ZnO}$ yielded an efficiency between $0.3 \%$ and $0.45 \%$. Solar cells fabricated with the above mentioned six different sensitizers were exposed to simulated solar light for periods of up to 30 days, and in the case of the Ru-N3 dye and nanocrystalline $\mathrm{TiO}_{2}$ substrate for periods of up to 280 days. Photochemical degradation was observed in all cases. It was clearly more pronounced in the case of $\mathrm{ZnO}$, even though simultaneously lower solar cell efficiencies were reached.

Figure 3(a) shows the integral photocurrent densityvoltage characteristics of a nanocrystalline zinc oxide cell sensitized with the $\mathrm{N} 3$ ruthenium complex at the beginning of the experiment and after 20 days of continuous exposure to simulated solar light.

During this period the integral photocurrent density decreased by $35 \%$. It is realized that basically only the photocurrent density decreased and not the photovoltage.

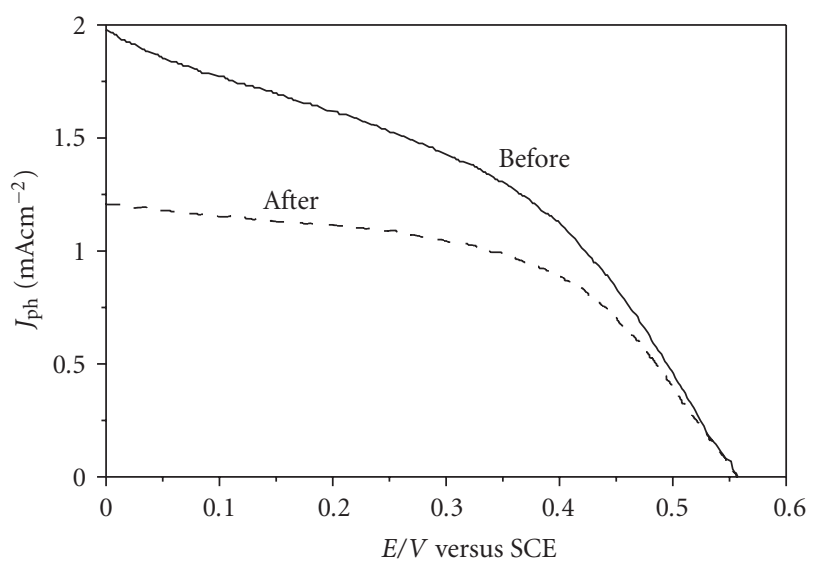

(a)

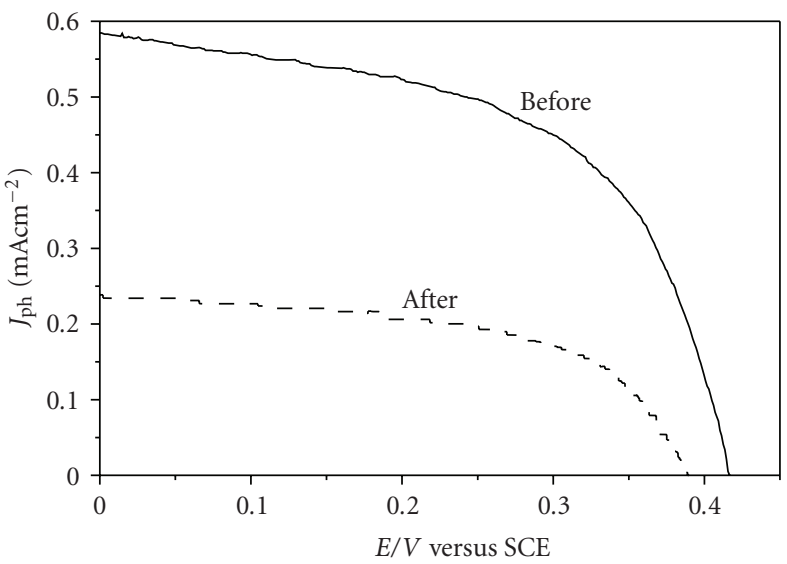

(b)

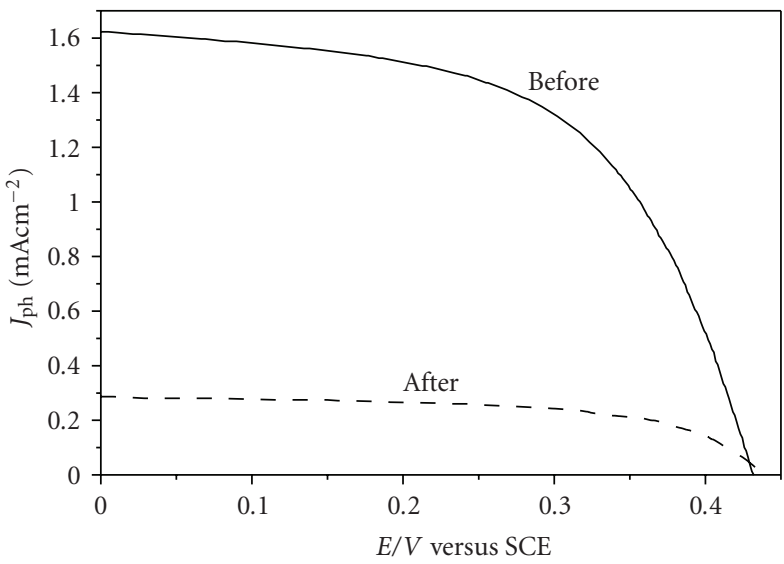

(c)

Figure 3: Power output characteristic (photocurrent voltage dependencies) of dye sensitized cells: (a) nanocrystalline $\mathrm{ZnO}, \mathrm{N} 3$ complex before and after 20 days of simulated solar illumination; (b) nanocrystalline $\mathrm{TiO}_{2}$, pyrogallol red before and after 11 days of simulated solar illumination; (c) nanocrystalline $\mathrm{TiO}_{2}$, copper chlorophylline before and after 30 days of simulated solar illumination. 

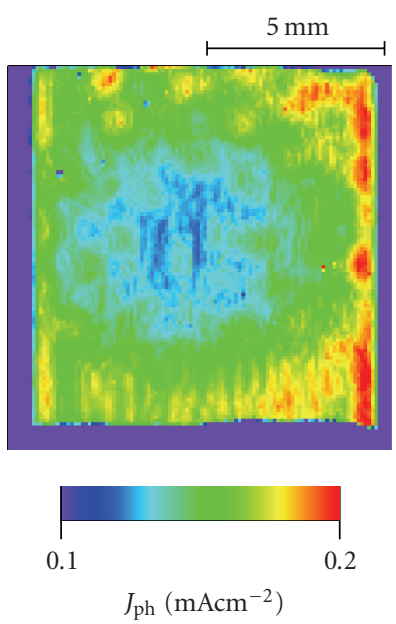

(a)

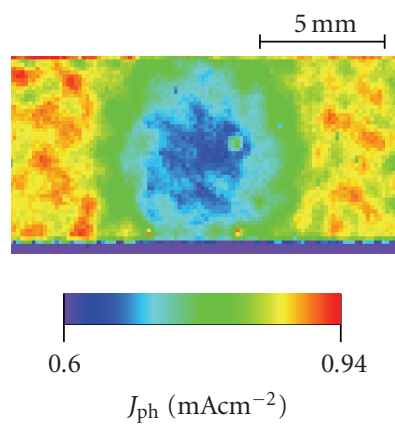

(c)

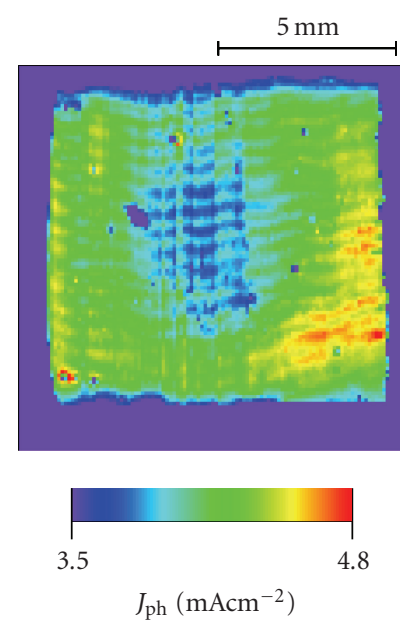

(b)

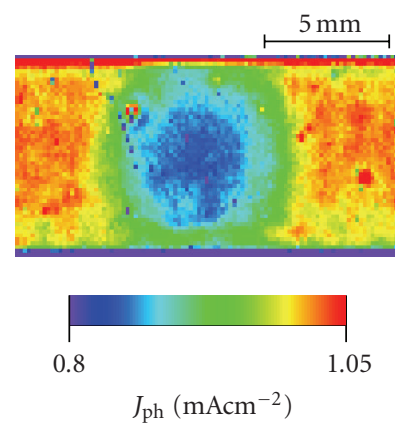

(d)

Figure 4: Photodegradation in photocurrent images of four regularly operating nanocrystalline $\mathrm{TiO}_{2}$ solar cells. Sensitization with N3-dye and illumination with simulated solar light in a round central areas only. Illumination periods: (a) 1008 hours; (b) 336 hours; (c) 1248 hours; (d) 1248 hours.

Figures 3(b) and 3(c) show similar degradation curves of the power output characteristics of a nanocrystalline $\mathrm{TiO}_{2}$ pyrogallol red cell and of a nanocrystalline $\mathrm{TiO}_{2}$ copper chlorophylline solar cell. In the first case, Figure 3(b), the period of simulated solar light exposure was 11 days, in the second case the cell was exposed to solar light for 30 days. All investigated dyes showed a gradual photochemical degradation when exposed to simulated solar light for a prolonged period.

Among the many dyes which have been screened, only a few approach the properties of $\mathrm{Ru}-\mathrm{N} 3$, as shown in Figure 2. Ru-N3 turned out to be the most favorable sensitizer, all other dyes exhibited lower efficiency and stronger degradation. Lower efficiencies and stronger degradation were also observed with nanocrystalline zinc oxide solar cells. Comparing different dyes, it was found that certain anchor groups like carboxyl or sulphone groups improve the sensitization properties of compounds. The interaction is apparently less efficient or of different nature with zinc oxide nanoparticles.

Special attention was dedicated to the degradation properties of the $\mathrm{N} 3$ ruthenium complex on nanocrystalline

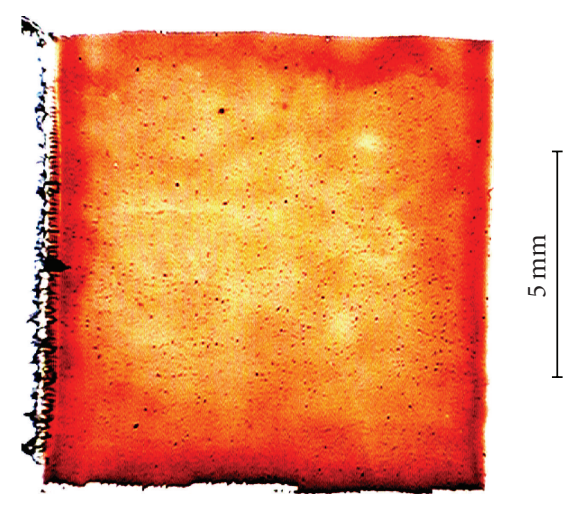

FIgURE 5: Video image of the cell in Figure 4(a), obtained under light transmission and after contrast amplification.

$\mathrm{TiO}_{2}$. Here, a long-term experiment, in which sensitized cells were exposed to simulated solar light during a period of 155 days, turned out to be especially informative. The cells were illuminated through a mask with a round opening in order to distinguish between illuminated and nonilluminated areas. During such long-term experiments, the instability of the iodide/triiodide electrolyte turned out to be a major problem. In some cases, depending on small variations in the preparation, the electrolyte was bleached so that the iodine largely disappeared from the electrolyte. This problem was investigated and may be understood in relation to the potential-pH diagram of iodine. Depending on traces of water which leak into the organic electrolyte through the seal from the outside, and due to the presence of tert.butylpyridine, a slightly alcaline $\mathrm{pH}$ can be developed, which allows oxidation of iodide to iodate $\left(\mathrm{IO}_{3}{ }^{-}\right)$. Since this iodate could not be detected spectroscopically in the electrolyte, it may have been adsorbed on the nanocrystalline $\mathrm{TiO}_{2}$ layer. Whatever the detailed mechanism of this process, it causes the disappearance of iodine and therefore the electron transport through the electrolyte became extremely limited.

In the above mentioned long-term experiment, four dye sensitized cells showed bleaching of the electrolyte, but were continuously operated under short-circuit conditions with a very small current flow. This means, since the photocurrent largely collapsed, that the bleached cells had a power output characteristic with low fill factor. At the end of the longterm experiment, all dye sensitized cells, both those that maintained good power output characteristics and those which were bleached and showed very unfavorable power output characteristics were investigated using the scanning laser technique to obtain photocurrent images. During these measurements, only a very small photocurrent generated by the laser spot (laser light intensity not exceeding solar light intensity) had to flow through the dye sensitized cell. Such a small current could also be maintained by those cells which had a bleached, iodine deficient electrolyte.

Figure 4 shows four dye sensitized cells (N3 ruthenium complex on nanocrystalline $\mathrm{TiO}_{2}$ ) which operated with unbleached electrolyte (Figures 4(a)-4(d)). For comparison, four cells in which the electrolyte was bleached during 

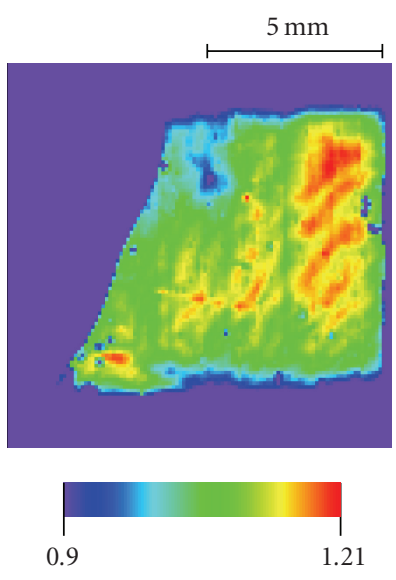

$J_{\mathrm{ph}}\left(\mathrm{mAcm}^{-2}\right)$

(a)
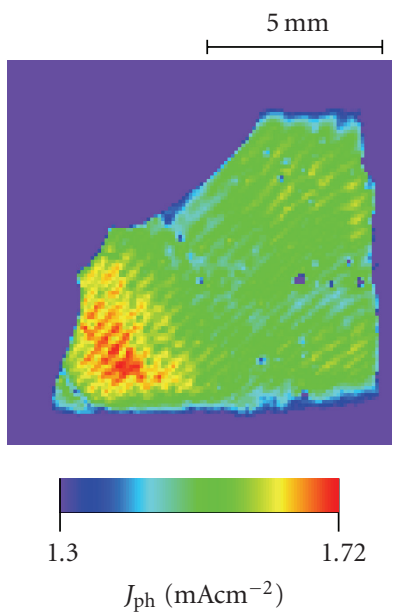

(c)
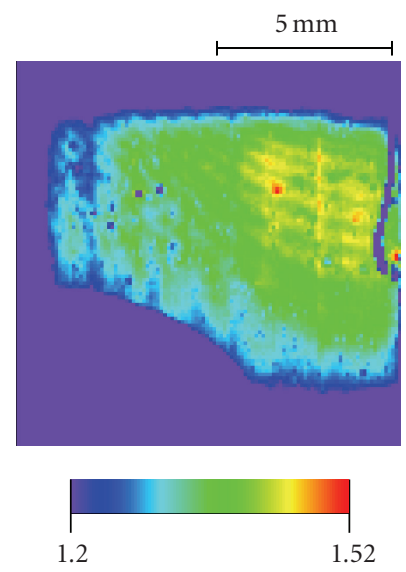

$J_{\mathrm{ph}}\left(\mathrm{mAcm}^{-2}\right)$

(b)

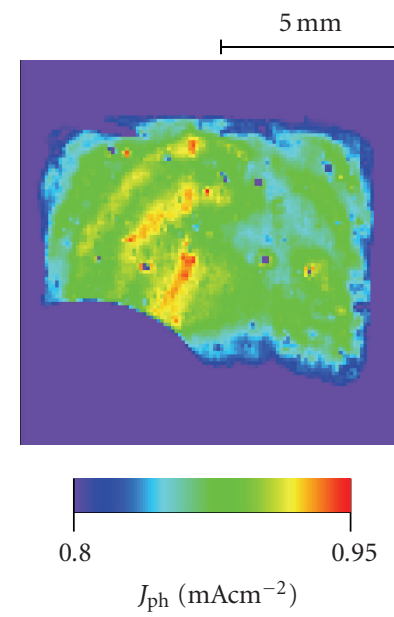

(d)

Figure 6: Photodegradation is not detected in photocurrent images of nanocrystalline $\mathrm{TiO}_{2}$ solar cells with bleached electrolyte, which causes significantly decreased photocurrent densities during illumination. All cells are sensitized with N3 dye and were illuminated with simulated solar light in round central areas only. The illumination period was 150 days (3600 hours). The cells were at the end not completely wetted with electrolyte.

long-term (3600 hours) illumination are shown in Figure 6. In the first case (Figure 4), photodegradation of the ruthenium complex within the round areas illuminated with simulated solar light can clearly be recognized while in the second case there is no evidence of a difference between illuminated and nonilluminated areas of the dye sensitized solar cell. The difference between the cells in Figures 4 and 6 is simply that in the first case photocurrent could be passed in an uninhibited way, while in the second case photocurrent passage was severely hindered due to lack of iodine. This shows that photons and thermal energy alone are not the primary cause of the degradation if electrons are allowed to react back. Because the mask for forming the light patterns was black and placed directly onto the cell, thermal energy was also generated outside the circular opening. The graded

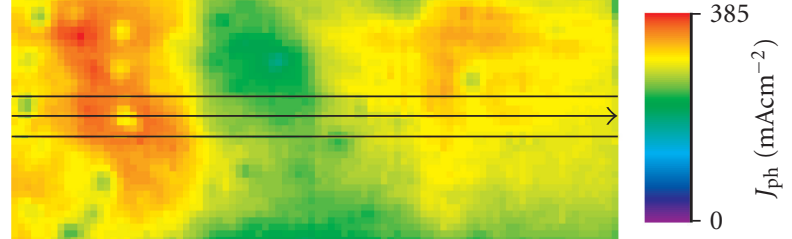

(a)

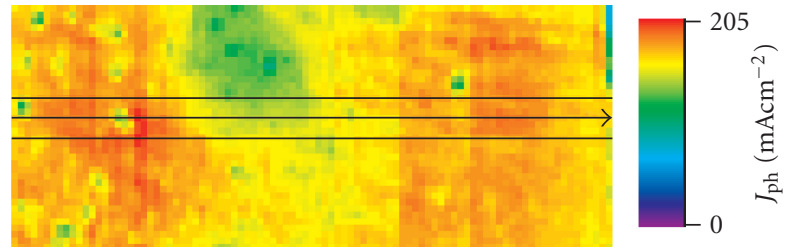

(b)

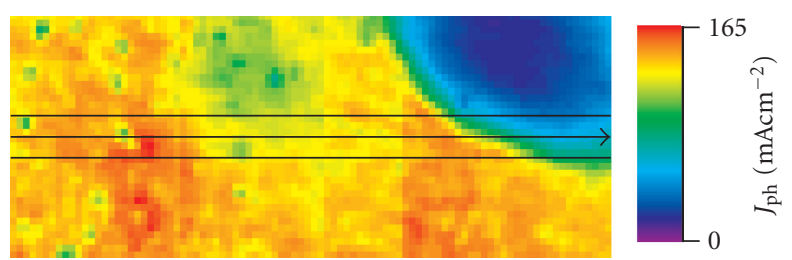

(c)

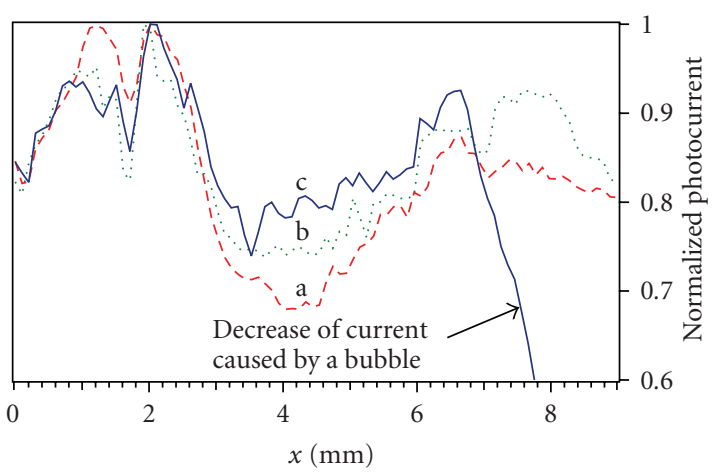

(d)

Figure 7: Photocurrent profiles at the same position across a dye sensitized solar cell with inhomogeneous photocurrent distribution. Measurements were done after different periods of illumination with simulated solar light. The photocurrent profiles smooth out during long-term photodegradation, because photodegradation is faster where large photocurrents are flowing. (Experiment performed with copper-chlorophylline on $\mathrm{TiO}_{2}$ ): (a) before and (b) after 21 days, and (c) after another 93 days of illumination with simulated solar light.

filter also absorbed light to generate thermal energy, so that temperature gradients across nonhomogenously illuminated solar cell surfaces were expected to be low.

The significant $15-30 \%$ photocurrent decrease observed during the long-term experiments (Figure 4) raises the question as to the optical visibility of the illuminated and degraded areas. Optical transmission was indeed changed.

As Figure 5 shows, after contrast amplification, the transmission pattern of the solar cell matches essentially the photocurrent pattern (Figure 4(a)). This video image 


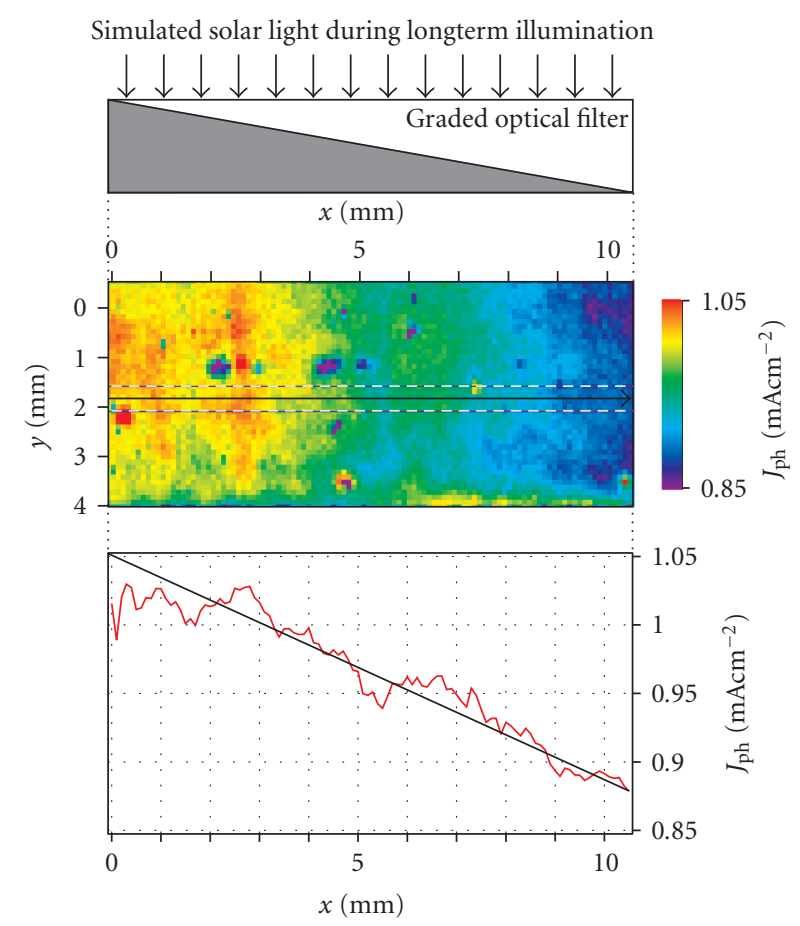

Figure 8: Nanocrystalline $\mathrm{TiO}_{2}-\mathrm{N} 3$ sensitized solar cell with graded filter placed on its surface after 1245 hours of exposure to simulated solar light. It is seen that photodegradation, measured as spatially resolved photocurrent output, is proportional to solar light intensity and thus the photocurrent passed.

(Figure 5) was obtained under light transmission, after cleaving of the cell, from only the front-half which consisted of ITO-glass and $\mathrm{TiO}_{2}$-layer with adsorbed dye. An influence of the electrolyte or back-contact platinum layer is therefore excluded. However, with the naked eye the transmission change has only occasionally been observed clearly. This means it stayed within a $1-2 \%$ limit, which leads to the conclusion that the deactivated sensitizer still absorbs light in the visible spectral region. The degraded complex is still present and has only moderately changed its absorption spectrum in the visible spectral region with respect to the sensitizer.

These results show that photodegradation of the sensitizer must be related to the generation of sensitization photocurrents through the cell. In the case that these photocurrents cannot be generated, which causes the effective rapid recycling of the electrons, photodegradation is suppressed. Therefore, it can be concluded that only the oxidized state of the sensitizer is critical for photodegradation.

In order to test this interesting observation, which may also be relevant for other sensitizers, two additional experiments were performed. In the first, dye sensitized cells with very inhomogeneous photocurrent distributions were investigated. If a higher photocurrent density also means a higher rate of photodegradation, a profile through such an inhomogeneous cell should smooth out during a prolonged illumination. This means the photocurrent in high-photocurrent-density regions should decrease faster

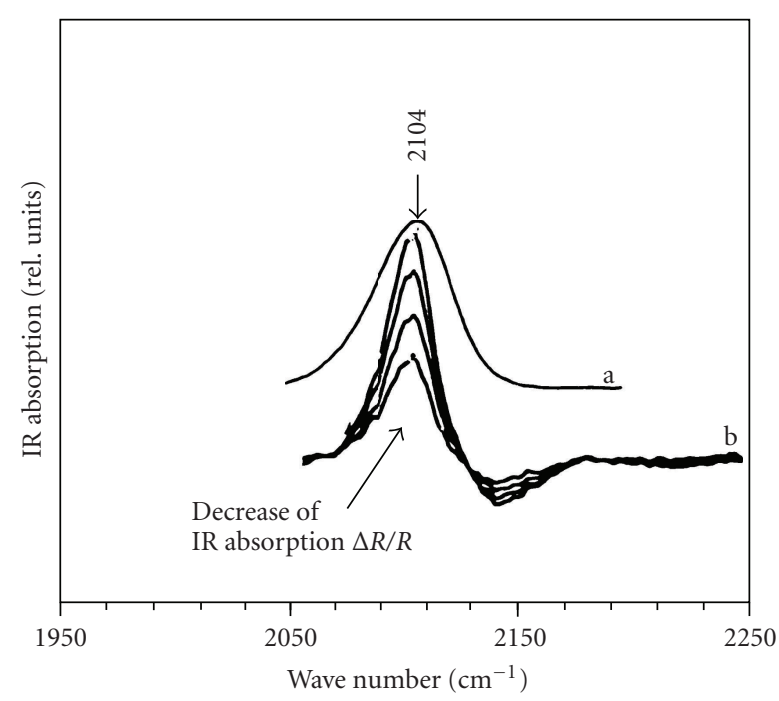

FIGURE 9: Shape of ex situ IR-CN stretch-line $\left(2104 \mathrm{~cm}^{-1}\right)$ of N3 sensitizer (a) compared to lineshape characteristic for photodegradation loss after passage of $1.4,5.4,9.5$, and $14 \mathrm{mC} \mathrm{cm}^{-2}$ of photoelectrical charge through the dye sensitized cell, (b) measured in total reflection FTIR-experiments.

than in lower-photocurrent-density regions. Such an experiment is demonstrated in Figure 7 showing the normalized photocurrent-profile through an inhomogeneous dye sensitized cell versus cell operation time. It is indeed recognized that the profiles smooth out with illumination time.

To confirm the conclusion that higher photocurrent flux means more degradation, a graded filter was placed onto an N3 dye sensitized cell for a long-term study. The cell with originally homogeneous photocurrent density distribution was exposed to simulated solar light attenuated by the graded optical absorption filter. Figure 8 shows that the spatially resolved photocurrent density measured after exposure of the cell to 1248 hours of simulated sunlight actually has a linear degradation profile. The laser-induced photocurrent decreases indeed proportional to the light intensity and thus to the magnitude of the photocurrent generated at the respective location. The higher the photocurrent density is, the higher the rate of degradation will be.

Total reflection infrared spectroscopy on functioning dye sensitized solar cells performed in our laboratory have demonstrated the occurrence of products parallel to photocurrent flow $[31,42]$. The integrated infrared signal disappears when the current density goes to 0 and increases with increasing photocurrent density. These results confirm that the generation of oxidation products is related to the extraction of electrons from the sensitizer's environment. Depending, however, on the specific adsorption sites, sensitizer molecules may be involved in quantitatively different reaction behavior. The loss peaks in the in situ spectrum at $1988 \mathrm{~cm}^{-1}$ and $2104 \mathrm{~cm}^{-1}$, with widths of $29 \mathrm{~cm}^{-1}$ and $26 \mathrm{~cm}^{-1}$, respectively, showed a somewhat smaller width than in the ex-situ spectrum where the width was $33 \mathrm{~cm}^{-1}$. This is shown in Figure 9 for the $2104 \mathrm{~cm}^{-1}$ line in the $\mathrm{CN}$-vibration region. It shows the line shape from an 

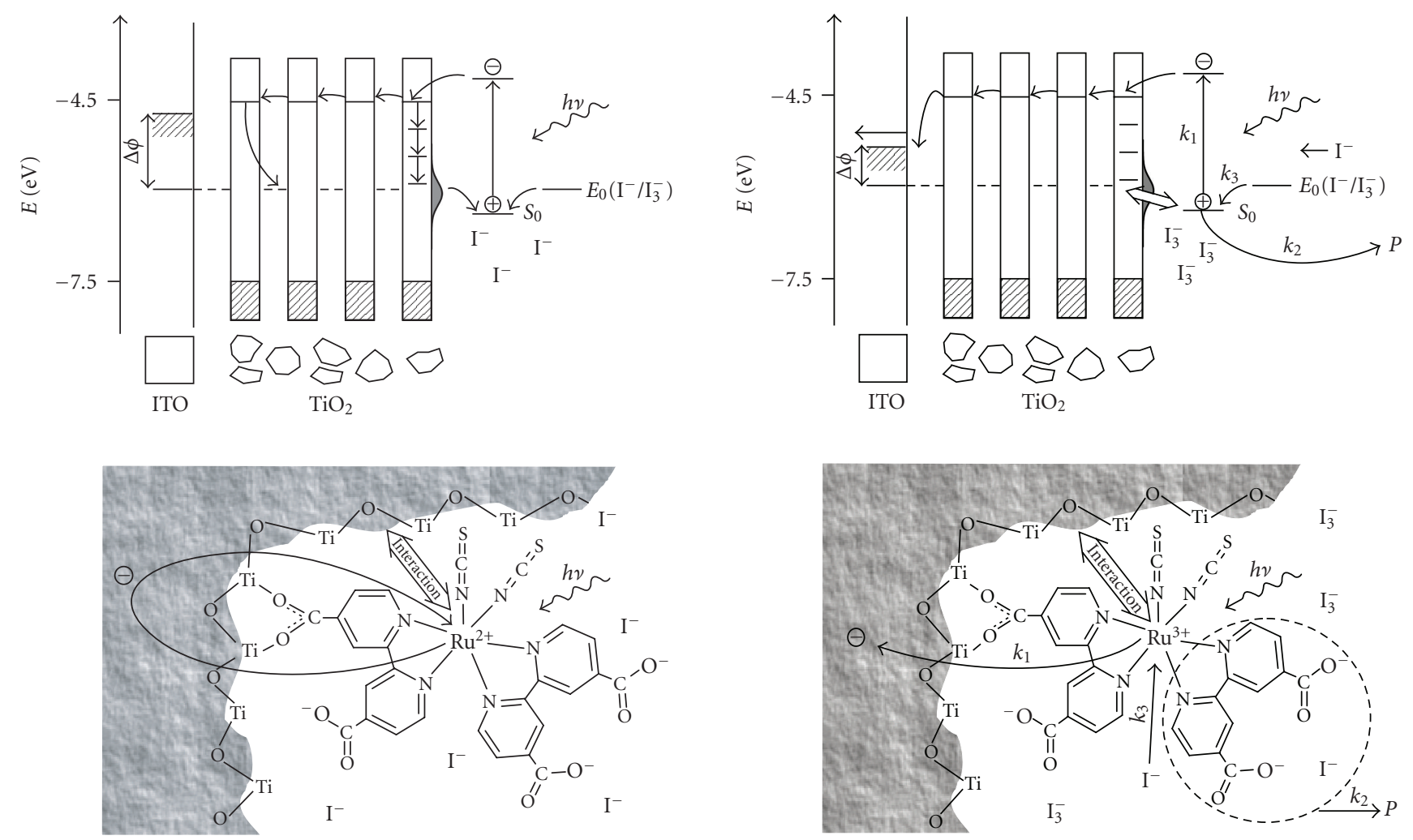

(a)

(b)

FIgUre 10: Compares the N3 ruthenium complex, both, in the state of rapid electron recovery (Figure 10(a)) and in the state of electron extraction via a reasonably high photocurrent flow (Figure 10(b)). While present in the $\mathrm{TiO}_{2}$ interphase, the injected electron may convert $\mathrm{Ti}^{4+}$ into $\mathrm{Ti}^{3+}$ enabling a back bonding reaction facilitating a temporary $\mathrm{Ti}^{3+}$ (ligand) $\mathrm{Ru}^{3+}$ charge transfer complex.

ex situ spectrum of cis- $\mathrm{Ru}^{\mathrm{II}}\left(\mathrm{dcbpyH}_{2}\right)_{2}(\mathrm{NCS})_{2}$ adsorbed on nanocrystals within a $1 \mu \mathrm{m}$ thin $\mathrm{TiO}_{2}$ layer. It also shows the decrease of this absorption (plotted, however, in the opposite direction to permit a better comparison of line shapes) from an in situ experiment after passing the photocharge of 1.4, 5.4, 9.5, and $14 \mathrm{mCcm}^{-2}$ through the dye sensitized cell. A clearly narrower IR line due to the consumption of the sensitizer is realized, indicating that a limited fraction of adsorbed molecules is selectively turned over. The molecules preferentially consumed during photocurrent flow are those, which are positioned around the center of the line and not those which, due to stronger interaction with the $\mathrm{TiO}_{2}$ substrate, are energetically positioned away from the center. This is clear evidence for the role of the $\mathrm{TiO}_{2}$ adsorption site in determining the stability of sensitizing molecules during the photoreaction.

\section{DISCUSSION}

The main aim of this study was to identify physical-chemical factors relevant for long-term stability or degradation of sensitizers of nanocrystalline $\mathrm{ZnO}$ and $\mathrm{TiO}_{2}$ solar cells to determine the influence of the adsorption site. The focus was on light-induced degradation. An analytical formula describing the nature of various cell parameters, and rate constants which may influence the photocurrent voltage characteristic, had been presented in an earlier publication [32]. The photodegradation of sensitizer molecules is just one possible mechanism of degradation. Other processes involve the kinetics of the rectifying front $\mathrm{TiO}_{2} /$ fluorinated tin oxide contact (it is very critical for the performance and long-term stability of the dye sensitized solar cell), insertion of alkali atoms into $\mathrm{TiO}_{2}$, irreversible changes of the redox electrolyte, loss of electrolyte, and contamination of the electrolyte from the atmosphere [19].

All sensitizers investigated in the present study, including the Ru-complex (N3), which presently is considered to be sufficiently stable for long-term (20 years) operation in dye sensitized cells, were found to degrade to varying extents. The N3 Ruthenium sensitizer turned out to be the most stable one, but it nevertheless photodegrades (Figure 4) and it degrades proportional to the photocurrent passed through the dye solar cell (Figure 8). This means that photodegradation will be the more pronounced the higher the cell efficiency.

Since this is a somewhat perturbing conclusion and since there have been persistent claims that the $\mathrm{Ru}$-dye does not photodegrade and supports $10^{8}$ turnovers, let us first discuss our results in relation to other recent studies on dye solar cell performance and stability [20-29]. They, for example, 
claim significant progress by using alternative electrolytes and improved sealing techniques (e.g., [20]). In this latter work, $0.6 \mathrm{M}$ hexylmethyl imidazolium iodide was added to the acetonitrile electrolyte and a glass frit sealing was used. In stead of exposing the solar cell as it is to the solar simulator, the cell was first exposed to $80^{\circ} \mathrm{C}$ in the dark (!) for 1400 hours, and subsequently exposed to light for 1700 hours at only $25^{\circ} \mathrm{C}$. The claim then was that the dye cell showed a photodegradation of less than 5\% during 1700 hours. In fact, the entire procedure (thermal treatment plus subsequent illumination at $25^{\circ} \mathrm{C}$ ) has decreased the solar cell efficiency by $20 \%$, as seen from [20, Figure 10].

In reality, however, strong sunshine can heat a dye solar cell to $80^{\circ} \mathrm{C}$, and the most damaging degradation process is the periodically daily heating and cooling of the dye solar cell under solar illumination.

For comparison, our solar cells, the selective degradation of which is depicted in Figures 4(c) and 4(d) decreased their photocurrents during 1248 hours of illumination and solar simulator determined higher temperature by approximately $10 \%$. It has also to be considered that photodegradation was found to be proportional to its efficiency and thus to the photocurrent density passed (compare Figure 8 ). In addition, we are confronting these results with nearly Redox inactive solar cells, which show practically no degradation after 3600 hours (Figure 6). Our stability results therefore appear to be entirely realistic and contradict possible claims, that more recent cell configurations have solved the stability problem. Since the most stable dye cell in [20] only had an efficiency of $2 \%$, our results also claim that a corresponding $8 \%$ solar cell will, under illumination, degrade 4 times faster, if a linear extrapolation is applicable. It will also degrade faster when illumination is not performed at $25^{\circ} \mathrm{C}$, but at an illumination up to 60 degree higher temperature, which can be reached in intensive sunlight.

In our work, it could be confirmed that anchoring groups of the dye support the sensitization effect but that the nanocrystalline $\mathrm{ZnO}$ interface is a less favorable substrate for electron injection and long-term stability of Ru-dyes under the investigated conditions. It has, for example, been suggested [43] that the $\mathrm{N} 3$ ruthenium complex tends to aggregate by reacting with zinc ions dissolved from the $\mathrm{ZnO}$ interface. The oxide surface is electronically and chemically significantly different for $\mathrm{TiO}_{2}$ and $\mathrm{ZnO}$, the latter of which additionally exposes polar surfaces terminating with $\mathrm{Zn}$ and $\mathrm{O}$, respectively. In our studies, degradation of this ruthenium complex is significantly faster on $\mathrm{ZnO}$ than on $\mathrm{TiO}_{2}$. This degradation is faster by a factor of 7 to 10 on $\mathrm{ZnO}$ when the same iodide/triiodide electrolyte in acetonitrile is used.

One reason why metal centered complexes (ruthenium complexes, copper chlorophylline complex) are more stable than sensitizers without transition metal centers may be due to coordination chemistry. The electron transfer occurs metal centred and involves states which are not essentially weakened by electron transfer. In addition, some coordinative interaction between iodide and oxidized metal centered sensitizers can occur. This allows a quite selective electron transfer which does not excessively weaken other bonding states. Nevertheless, as shown in the literature [44], a ruthenium complex can undergo approximately 143 transitions involving different ligand configurations. Depending on the type of transition involved in the sensitization reaction, the oxidized product may have variable survival lifetimes because they involve different portions of the ligand environment. Figure 9 shows that not all sensitizer molecules at different adsorption sites of the $\mathrm{TiO}_{2}$ environment are equally affected. This means that the reaction kinetics of molecules is dependent on the type of adsorption sites. Molecules which do not inject electrons or molecules which are immediately regenerated will not participate in the generation of the in situ infrared signal. Others, due to their peculiar adsorption position, may show preferred tendency towards product formation, that is, they may show a large $k_{2}$ rate constant and thus contribute to a decrease of life time (1) of dye sensitized cells, formulated below. The interface of $\mathrm{ZnO}$ apparently provides more unfavorable reaction possibilities. Alternatively, it may also be that the N3 dye has an especially favorable affinity to $\mathrm{TiO}_{2}$. From Figure 9 it may be tentatively deduced that the weakly interacting N3 molecules and not the strongly interacting (large deviation from mean position of IR band) are preferentially lost to photodegradation. It may be that these molecules, after losing the injected electron, tend to irreversibly react, involving the chemistry of the interface. Recent HPLC-chromatic studies combined with UV/VIS-spectroscopy of N3-dye samples extracted from long-term illuminated solar cells have detected a variety of products which may have formed this way [45]. In this case, the interface of the substrate should be critical, which is indeed supported by the much higher degradation rate of N3 on nanocrystalline $\mathrm{ZnO}$. Such an effect of the oxide interface on the rate $k_{2}$ of product formation could also explain why at the beginning of a long-term experiment the rate of photodegradation, as reflected in the branching coefficient $k_{\mathrm{br}}$ from relation (1), appears to be larger in some experiments before levelling off [30]. The reason may be that photo-oxidized molecules at selected surface sites, which provide an adequate surface environment, will more easily find reaction possibilities towards irreversible products.

Interestingly, however, as seen from Figure 6, degradation ceases (at least for the time window observed) when photocurrent flow through the cell is suppressed while all other parameters are maintained. This is a very important observation which has to be discussed in some detail. It explains why accelerated dye sensitized solar cell tests under high-illumination intensity, but under opencircuit conditions (no photocurrent flow), yielded no evident degradation and turnover numbers for electrons of the order of $10^{8}$. This would be necessary for a solar cell operation of 20 years [17]. Complementarily, experiments in Figure 4 clearly show that when photocurrent flows, the stability of the sensitizer is reduced. This is in agreement with the formula for the half-lifetime of a dye sensitized solar cell which has earlier been proposed [32]:

$$
T_{1 / 2}^{0} \sim \frac{S_{0}}{j_{\mathrm{ph} 0}} k_{\mathrm{br}} \sim \frac{S_{0}}{j_{\mathrm{ph} 0}} \cdot \frac{k_{3} \mathrm{I}^{-}}{k_{2}}
$$


with the branching coefficient $k_{\mathrm{br}}=k_{3}\left[\mathrm{I}^{-}\right] / k_{2}$ for the assumed simplest sensitizer reaction, $S_{0}=$ initial sensitizer concentration, $j_{\mathrm{ph} 0}=$ initial photocurrent density, $P=$ product for the reaction sequence

$$
\begin{gathered}
h v+S \stackrel{g}{\longrightarrow} S^{*} \\
S^{*} \stackrel{k_{1}}{\longrightarrow} S^{+}+\mathrm{e}^{-} \\
S^{+} \stackrel{k_{2}}{\longrightarrow} P \\
S^{+}+\mathrm{I}^{-} \stackrel{k_{3}}{\longrightarrow} S+\frac{1}{2} \mathrm{I}_{2} .
\end{gathered}
$$

Relation (1) shows that the half lifetime of the dye sensitized cell is proportional to the initial concentration $S_{0}$ of the sensitizer in the nanostructure and inversely proportional to the initial photocurrent density. The perturbing fact is that the lifetime of the cell will be the shorter the higher its efficiency (and thus the photocurrent passing through it). This is clearly demonstrated by the graded filter experiment of Figure 8. The most successful long-term experiment of an optimized dye solar cell in [20] (1700 hours of solar illumination at only $25^{\circ} \mathrm{C}$ yielding less than $5 \%$ of degradation) was achieved with a cell of only $2 \%$ efficiency. A higher efficiency (photocurrent drawn) will correspondingly accelerate photodegradation. Depending on the temperature dependence of $k_{2}$ and $k_{3}$ in (2), the life time of the solar cell will be correspondingly temperature-dependent.

Additionally, it has to be considered that the rate of product formation, $k_{2}$, will be influenced by the chemistry of the oxide/electrolyte interface (compare Figures 3(a) and 4, and 9), so that $k_{2}=k_{2}$ (oxide interface). Considering relation (1), it has also to be pointed out that the amount $S_{0}$ of sensitizer in the nano-oxide layer may codetermine the initial degradation behavior of a cell. If the absorber layer is sufficiently thick and well be covered with dye molecules, excess sensitizer molecules may gradually and temporarily replace oxidized ones as sensitizers.

As discussed elsewhere [32], this branching coefficient may actually still be one order of magnitude too small to guarantee a 20 year lifetime of an efficient dye sensitized solar cell based on the N3 complex. But it turned out to be already surprisingly large for Ru-dyes, when compared with other sensitizers. However, the important finding that the sensitizer stability depends on the photocurrent density, and thus on the solar cell efficiency, explains, why further research on sensitizer stability is urgently needed. The instability problems are expected be the larger the higher dye solar cell efficiency, which is a critical factor for commercialization.

More recent systematic stability studies on dye sensitized cells performed [46] also show a clear dependence of degradation on the nature of the electrolyte (within 2 months approximately $40 \%$ in acetonitrile, $20 \%$ in propionitrile, $25 \%$ in methoxypropionitrile, and $75 \%$ in methoxyacetonitrile). But another study claims stability over 1000 hours at high efficiency [47] using a nonvolatile unspecified electrolyte. The experiments in this case were performed at $60^{\circ} \mathrm{C}$ during illumination, or at $80^{\circ} \mathrm{C}$ in the dark only. Real problems are to be expected and are actually found when the cell is allowed to heat to $80^{\circ} \mathrm{C}$ and beyond during periodic daylight illumination, where complex instability problems arise [48]. Only one of the problems involved concerns, in this case, the dye.

If the simplified relation ( 1 ) is applied, the expected rate of dye degradation is inversely proportional to the half life time and thus

$$
k_{\mathrm{degr}}^{0} \sim \frac{k_{2} j_{\mathrm{ph} 0}}{S_{0} k_{3}\left[\mathrm{I}^{-}\right]} .
$$

This means it is determined, besides on the iodide concentration, by the reaction rates $k_{2}$ and $k_{3}$, both of which should depend on the nature of the electrolyte as well as on the interfacial chemistry of the sensitizer adsorbed to oxide nanoparticles, and, of course, also on the temperature. It also follows that a negligible photocurrent will not induce significant degradation, as observed by comparing Figures 4 with 6. This, of course, explains why low-efficient dye solar cells yielded an apparent good long-term stability [17, 20]. But in order to understand reported good long-term stability at high current density [46], we have to assume a high rate of regeneration $k_{2}$ and a low rate of product formation $k_{3}$. Both rates may depend on interfacial properties of the nano-oxides. In addition, a surplus of sensitizer $S_{0}$ in solar cells $\left(S_{0}\right.$ in $\left.(3)\right)$ with a thick $(15-20 \mu \mathrm{m}) \mathrm{TiO}_{2}$ layer should theoretically be of advantage. However, it was found that, simultaneously, regeneration of $S^{+}$by $\mathrm{I}^{-}$is faced with transport problems, which lead to enhanced degradation with increasing layer $\mathrm{TiO}_{2}$ thickness [49].

A puzzling result from our studies, apart from the fact that initial sensitizer degradation is faster than the later ongoing one, is that the same $\mathrm{N} 3$ dye is from 7 to 10 times less stable on $\mathrm{ZnO}$ compared with $\mathrm{TiO}_{2}$ and also appears to depend on $\mathrm{TiO}_{2}$ preparation. This means, for example, that the oxidation product of $\mathrm{N} 3$ generated on $\mathrm{TiO}_{2}$ (Figure $10(\mathrm{~b})$ ) is different in its behavior from that formed on $\mathrm{ZnO}$. This must indeed be concluded since, in both cases, electron transfer to the $\mathrm{TiO}_{2}$ occurs in the pico to femtosecond range via the same carboxyl bridges, and since the possibly slightly different bond strength of which should only have a small influence on the life time of the large oxidized N3 molecule. Second, the initially faster degradation rate of $\mathrm{N} 3$ on $\mathrm{TiO}_{2}$, and the difference in N3 degradation on differently prepared and inhomogeneous $\mathrm{TiO}_{2}$ layers indicate that the specific surface chemistry and surface morphology of nano- $\mathrm{TiO}_{2}$ should be critical. Therefore, it had to be investigated how the oxidized N3 species (Figure 10(b)) could differently interact with the $\mathrm{TiO}_{2}$ and $\mathrm{ZnO}$, respectively, to which an electron has previously been donated.

What this interaction could involve has been studied in a parallel paper [50]. Photocapacitive techniques (oxide layers exposed to a gas phase studied in capacitive setup) were applied to study sensitized $\mathrm{TiO}_{2}$ and $\mathrm{ZnO}$ layers in contact with a controlled gas phase. When oxygen was removed from the gas phase, formation of $\mathrm{Ti}^{3+}$ states could be spectroscopically observed within the energy gap. When oxygen was removed in presence of the $\mathrm{N} 3$ sensitized $\mathrm{TiO}_{2}$, it was found that the $\mathrm{N} 3$ dye forms a charge transfer complex with $\mathrm{Ti}^{3+}$ (generated by oxygen extraction from $\mathrm{TiO}_{2}$ into 
the gas phase) in the $\mathrm{TiO}_{2}$ nanomaterial surface. This charge transfer complex formation is accompanied by a significant $(0.4 \mathrm{eV})$ broadening of the $\mathrm{N} 3$ absorption band.

This phenomenon of a charge transfer complex (Figure 10(b)) turned out to be entirely reversible and disappeared when oxygen was added again to the gas phase bordering $\mathrm{TiO}_{2}$, so that $\mathrm{Ti}^{3+}$ states were reconverted into $\mathrm{Ti}^{4+}$ states. This remarkable effect was only observed with the N3 dye and not observed with $\mathrm{ZnO}$ nor was it observed with metal cation-free dyes (Pyrogallol, Carmine) studied on the same $\mathrm{TiO}_{2}$.

Our interpretation for the exceptional stability of N3 (and related $\mathrm{Ru}$-based dyes) on $\mathrm{TiO}_{2}$ is therefore tentatively the following: when excited N3 is transferring an electron to $\mathrm{TiO}_{2}$ (Figure 10(b)), $\mathrm{Ti}^{4+}$ may be locally reduced to $\mathrm{Ti}^{3+}$, which now, via its d-state, can get involved in back bonding with the oxidized $\mathrm{N} 3$, so that a $\mathrm{Ti}^{3+}$-ligand- $\mathrm{Ru}^{3+}$ charge transfer complex is formed. This is a kind of microscopic feedback reaction. Macroscopically, an autocatalytic (feedback) process leads to selforganization and to a local export of entropy. This creates local order. This may also happen on a microscopic, macromolecular level. The feedback coupling (backbonding of the $\mathrm{Ti}^{3+} \mathrm{d}$-state with the oxidized N3 dye) may stabilize the oxidized N3 species, which temporarily forms a complex with (reduced) $\mathrm{TiO}_{2}$. This could explain the longer survival of $\mathrm{N} 3$ sensitizer molecules on $\mathrm{TiO}_{2}$ compared to $\mathrm{ZnO}$ in an entirely consistent way. As this phenomenon of a backbonding of N3 and of N3 stabilization had been predicted [51] in 2004 long before the relevant experiments were made [50], this adds credibility to the here discussed charge transfer hypothesis, which is clearly different from the traditional approach to understand electron injection from $\mathrm{Ru}(\mathrm{dcbpy})_{2} \mathrm{X}_{2}$ with $\left(\mathrm{X}_{2}=2 \mathrm{SCN}, 2 \mathrm{CN}\right.$ or dcbpy) into $\mathrm{TiO}_{2}$ [52]. It occurs within less than 100 femtoseconds, and sensitization efficiency was found to be dependent on the redox potential of the sensitizer. The latter observation [52] could also be consistent with the here discussed model of a charge transfer complex.

We may talk of a light-induced charge transfer complex formation of N3 on $\mathrm{TiO}_{2}$ nanoparticles. Since $\mathrm{TiO}_{2}$ nanomaterials require a temperature treatment for favorable sensitizer adsorption it may be that the $\mathrm{TiO}_{2}$ surface has to be especially activated or optimized with respect to the chargetransfer interaction proposed. There may consequently be more favorable and less favorable nano- $\mathrm{TiO}_{2}$ substrates.

On the basis of these new viewpoints on the stability of the dye solar cell, it is interesting to reconsider the development history of dye solar cells. The discovery of the improved efficiency and stability of dye solar cells using $\mathrm{N} 3$ and related Ru-based sensitizers [16] was essentially a chance discovery, based on a favorable combination of $\mathrm{Ru}$ sensitizer and with $\mathrm{TiO}_{2}$. Before, dye solar cell experiments did not encourage major efforts, because the sensitizers were not sufficiently stable on sintered $\mathrm{ZnO}$ substrates [14] and earlier studies of $\mathrm{Ru}$-dyes on $\mathrm{TiO}_{2}$ [15] did not use the most favorable electrolytes. It also explains the comparatively flat learning curve [51] for the dye solar cell development, resulting from not recognizing the essential research targets. It equally explains why, after 15 years of intensive research on the Grätzel cell [16], with much effort in direction of cheaper dyes, expensive ruthenium-based complexes (approx. $1000 \$$ per gram) are still the preferred sensitizers.

Now the crucial role of $\mathrm{TiO}_{2}$ chemistry should be highlighted: the most essential difference between sensitization of $\mathrm{ZnO}$ and of $\mathrm{TiO}_{2}$ will be a higher life time of the oxidized N3 complex on $\mathrm{TiO}_{2}$ due to the formation of the proposed lightinduced $\mathrm{Ti}^{3+}$ (ligand) $\mathrm{Ru}^{3+}$ charge transfer complex [50]. While optimizing the expensive Ru-dye further for still higher stability is a possible strategy, a preferable initiative would be to learn to get cheaper metal containing dyes reasonably charge transfer stabilized while reacting on $\mathrm{TiO}_{2}$ surfaces. Can suitable alternative charge transfer complexes be designed to work with cheaper dyes containing more abundant transition metals?

For answering this question the here proposed mechanism will have to be studied theoretically and experimentally in greater detail. Since the nano- $\mathrm{TiO}_{2}$ surface is critical for the formation of the charge transfer complex and for the rate of reaction $\left(k_{2}\right)$ for formation of the oxidized sensitizer, it needs increased attention. Specifically, it should also be investigated, whether doping with transition metal ions, which can engage in d-state backbonding with the sensitizer, can increase sensitizer stability.

Interestingly, the here demonstrated influence of the nature of the absorption sites on the photochemical degradation of sensitizers has already been recognized in an early study, 35 years ago, on $\mathrm{ZnO}$ single crystals sensitized with chlorophyll [5]. From the degradation curve of chlorophyll sensitized electrodes, it was deduced that sensitizer molecules with widely different stabilities were active on the oxide surface.

In the future, the electronic properties of $\mathrm{TiO}_{2}$ nanoparticle surfaces will have to be optimized for increased sensitizer stability and specific new sensitizer complexes should be tailored if advantage should be taken of the potentially low costs projected for dye solar cells.

\section{REFERENCES}

[1] H. Meier, "Sensitization of electrical effects in solids," Journal of Physical Chemistry, vol. 69, no. 3, pp. 719-729, 1965.

[2] H. Meier, Spectral Sensitization, The Focal Press, London, UK, 1967.

[3] H. Gerischer, M. Michel-Beyerle, E. Rebentrost, and H. Tributsch, "Sensitization of charge injection into semiconductors with large band gap," Electrochimica Acta, vol. 13, no. 6, pp. 1509-1515, 1968.

[4] H. Tributsch and H. Gerischer, "The use of semiconductor electrodes in the study of photochemical reactions," Berichte der Bunsen-Gesellschaft für Physikalische Chemie, vol. 73, pp. 850-854, 1969.

[5] H. Tributsch and M. Calvin, "Electrochemistry of excited molecules: photo-electrochemical reactions of chlorophylls," Photochemistry and Photobiology, vol. 14, no. 2, pp. 95-112, 1971.

[6] H. Tributsch, "Reaction of excited chlorophyll molecules at electrodes and in photosynthesis," Photochemistry and Photobiology, vol. 16, no. 4, pp. 261-269, 1972. 
[7] M. Grätzel, "Light and energy, dye sensitized solar cells mimic natural photosynthesis," in Proceedings of "Solar Energy and Artificial Photosynthesis", Satellite Meeting of the SEB 14th International Congress on Photosynthesis (PS '07), The Royal Society, London, UK, July 2007.

[8] H. Tsubomura, M. Matsumura, Y. Nomura, and T. Amamya, "Dye sensitised zinc oxide: aqueous electrolyte: platinum photocell," Nature, vol. 261, pp. 402-403, 1976.

[9] T. Watanabe, T. Miyasaka, A. Fujishima, and K. Honda, "Photoelectrochemical study on chlorophyll monolayer electrodes," Chemistry Letters, vol. 7, no. 4, pp. 443-446, 1978, (Japan).

[10] N. Alonso-Vante, M. Beley, P. Chartier, and V. Ern, "Dye sensitization of ceramic semiconducting electrodes for photoelectrochemical conversion," Revue de Physique Appliquée, vol. 16, pp. 5-10, 1981.

[11] M. Nakao, K. Itoh, and K. Honda, "Effect of donor density of semiconductor on spectralsensitization photocurrent," Denki Kagaku Oyobi Butsuri Kagaku, vol. 52, p. 378, 1984.

[12] M. T. Spitler and B. A. Parkinson, "Efficient infrared dye sensitization of van der Waals surfaces of semiconductor electrodes," Langmuir, vol. 2, no. 5, pp. 549-553, 1986.

[13] K. Itoh, M. Nakao, and K. Honda, "Preparation of $\mathrm{ZnO}$ thin-film transparent electrodes and their application to electrochemical spectral sensitization," Denki Kagaku Oyobi Butsuri Kagaku, vol. 52, p. 382, 1984.

[14] M. Matsumura, S. Matsudaira, H. Tsubomura, M. Takata, and H. Yanagida, "Dye sensitization and surface structures of semiconductor electrodes," Industrial \& Engineering Chemistry. Product Research and Development, vol. 19, no. 3, pp. 4157-421, 1980.

[15] M. P. Dare-Edwards, J. B. Goodenough, A. Andrew, K. R. Seddon, and R. D. Wright, "Sensitisation of semiconducting electrodes with ruthenium-based dyes," Faraday Discussions of the Chemical Society, vol. 70, pp. 285-298, 1981.

[16] B. O'Regan and M. Grätzel, "A low-cost, high-efficiency solar cell based on dye-sensitized colloidal $\mathrm{TiO}_{2}$ films," Nature, vol. 353, pp. 373-740, 1991.

[17] O. Kohle, M. Grätzel, A. F. Meyer, and T. B. Meyer, “The photovoltaic stability of, bis(isothiocyanato)rlutheniurn(II)-bis-2, 2'bipyridine-4, 4'-dicarboxylic acid and related sensitizers," Advanced Materials, vol. 9, no. 11, pp. 904-906, 1997.

[18] R. Eichberger and F. Willig, "Ultrafast electron injection from excited dye molecules into semiconductor electrodes," Chemical Physics, vol. 141, no. 1, pp. 159-173, 1990.

[19] B. Macht, M. Turrion, A. Barkschat, P. Salvador, K. Ellmer, and H. Tributsch, "Patterns of efficiency and degradation in dye sensitization solar cells measured with imaging techniques," Solar Energy Materials and Solar Cells, vol. 73, no. 2, pp. 163$173,2002$.

[20] J. Sastrawan, J. Beier, U. Belledin, et al., "New interdigital design for large area dye solar modules using a lead-free glass frit sealing," Progress in Photovoltaics: Research and Applications, vol. 14, no. 8, pp. 697-709, 2006.

[21] T. Toyoda, T. Sano, J. Nakashima, et al., "Outdoor performance of large scale DSC modules," Journal of Photochemistry and Photobiology A, vol. 164, no. 1-3, pp. 203-207, 2004.

[22] P. Wang, C. Klein, R. Humphrey-Baker, M. Zakeeruddin, and M. Grätzel, "Stable $\geq 8 \%$ efficient nanocrystalline dyesensitized solar cell based on an electrolyte of low volatility," Applied Physics Letters, vol. 86, no. 12, Article ID 123508, 3 pages, 2005.
[23] P. Wang, S. M. Zakeeruddin, J. E. Moser, M. K. Nazeeruddin, T. Sekiguchi, and M. Grätzel, "A stable quasi-solid-state dyesensitized solar cell with an amphiphilic ruthenium sensitizer and polymer gel electrolyte," Nature Materials, vol. 2, pp. 402407, 2003.

[24] G. E. Tulloch, "Light and energy-dye solar cells for the 21st century," Journal of Photochemistry and Photobiology A, vol. 164, no. 1-3, pp. 205-219, 2004.

[25] K. Okada, H. Matsui, T. Kawashima, T. Ezure, and N. Tanabe, "100 mm × $100 \mathrm{~mm}$ large-sized dye sensitized solar cells," Journal of Photochemistry and Photobiology A, vol. 164, no. 13, pp. 193-198, 2004.

[26] M. Spath, P. M. Sommerling, J. A. M. van Roosmalen, et al., "Reproducible manufacturing of dye-sensitized solar cells on a semi-automated baseline," Progress in Photovoltaics: Research and Applications, vol. 11, no. 3, pp. 207-220, 2003.

[27] S. Dai, K. Wang, J. Weng, et al., "Design of DSC panel with efficiency more than 6\%," Solar Energy Materials and Solar Cells, vol. 85, no. 3, pp. 447-455, 2005.

[28] Y. Chiba, A. Islam, R. Comiya, N. Koide, and L. Han, "Conversion efficiency of $10.8 \%$ by a dye-sensitized solar cell using a $\mathrm{TiO}_{2}$ electrode with high haze," Applied Physics Letters, vol. 88, no. 22, Article ID 223505, 3 pages, 2006.

[29] M. Wei, J. Konishi, H. Zhou, M. Janagida, H. Siguhara, and H. Arakawa, "Highly efficient dye-sensitized solar cells composed of mesoporous titanium dioxide," Journal of Materials Chemistry, vol. 16, pp. 1287-1293, 2006.

[30] M. Turrion, B. Macht, P. Salvador, and H. Tributsch, "Imaging techniques for the study of photodegradation of dye sensitization cells," Zeitschrift fur Physikalische Chemie, vol. 212, no. 1, pp. 51-57, 1999.

[31] R. Grünwald and H. Tributsch, "Mechanisms of instability in Ru-based dye sensitization solar cells," Journal of Physical Chemistry B, vol. 101, no. 14, pp. 2564-2575, 1997.

[32] H. Tributsch, "Function and analytical formula for nanocrystalline dye-sensitization solar cells," Applied Physics A, vol. 73, no. 3, pp. 305-316, 2001.

[33] E. Rijnberg, J. M. Kroon, J. Wienke, et al., "More stability measurements were described," in Proceedings of the 2nd European Photovoltaic Solar Energy Conference and Exhibition (PVSEC '98), p. 47, Vienna, Austria, July 1998.

[34] S. A. Haque, Y. Tachibana, R. L. Willis, et al., "Parameters influencing charge recombination kinetics in dye-sensitized nanocrystalline titanium dioxide films," Journal of Physical Chemistry B, vol. 104, no. 3, pp. 538-547, 2000.

[35] A. Hinsch, J. M. Kroon, R. Kern, et al., "Long-term stability of dye-sensitised solar cells," Progress in Photovoltaics: Research and Applications, vol. 9, no. 6, pp. 425-438, 2001.

[36] H. G. Agrell, J. Lindgren, and A. Hagfeldt, "Degradation mechanisms in a dye-sensitized solar cell studied by UV-VIS and IR spectroscopy," Solar Energy, vol. 75, no. 2, pp. 169-180, 2003.

[37] C. Barbé, F. Arendse, P. Comte, et al., "Nanocrystalline titanium oxide electrodes for photovoltaic applications," Journal of the American Ceramic Society, vol. 80, no. 12, pp. 3157-3171, 1997.

[38] N. Papageorgiou, W. F. Maier, and M. Grätzel, "An iodine/triiodide reduction electrocatalyst for aqueous and organic media," Journal of the Electrochemical Society, vol. 144, no. 3, pp. 876-884, 1997.

[39] M. A. Anderson, M. J. Gieselmann, and Q. J. Xu, "Titania and alumina ceramic membranes," Journal of Membrane Science, vol. 39, no. 3, pp. 243-258, 1988. 
[40] B. O’Regan, J. Moser, J. Anderson, and M. Grätzel, "Vectorial electron injection into transparent semiconductor membranes and electric field effects on the dynamics of light-induced charge separation," Journal of Physical Chemistry, vol. 94, no. 24, pp. 8720-8726, 1990.

[41] A. M. Chaparro, P. Salvador, and A. Mir, "Localized photoelectrochemical etching with micrometric lateral resolution on transition metal diselenide photoelectrodes," Journal of Electroanalytical Chemistry, vol. 422, no. 1-2, pp. 35-44, 1997.

[42] R. Grünwald, Ph.D. thesis, Freie Universität, Berlin, Germany, 1997.

[43] K. Keis, J. Lindgren, S. E. Lindquist, and A. Hagfeldt, "Studies of the adsorption process of Ru complexes in nanoporous $\mathrm{ZnO}$ electrodes," Langmuir, vol. 16, no. 10, pp. 4688-4694, 2000.

[44] G. Calzaferri and R. Rytz, "Electronic transition oscillator strength by the extended Hueckel molecular orbital method," Journal of Physical Chemistry, vol. 99, no. 32, pp. 12141-12150, 1995.

[45] M. Thomalla and H. Tributsch, "Chromatographic studies of photodegradation of $\mathrm{RuL}_{2}(\mathrm{SCN})_{2}$ in nanostructured dyesensitization solar cells," Comptes Rendus Chimie, vol. 9, no. 56, pp. 659-666, 2006.

[46] R. Kern, N. van der Burg, G. Chmiel, et al., "Long term stability of dye-sensitised solar cells for large area power applications," Opto-Electronics Review, vol. 8, no. 4, pp. 284288, 2000.

[47] D. Kuang, C. Klein, S. Ito, et al., "High-efficiency and stable mesoscopic dye-sensitized solar cells based on a high molar extinction coefficient ruthenium sensitizer and nonvolatile electrolyte," Advanced Materials, vol. 19, no. 8, pp. 1133-1137, 2007.

[48] P. M. Sommerling, M. Späth, H. J. P. Smit, N. J. Bakker, and J. M. Kroon, "Long-term stability testing of dye-sensitized solar cells," Photochemistry and Photobiology A, vol. 164, no. 1-3, pp. 137-144, 2004.

[49] M. Junghaenel and H. Tributsch, "Role of nanochemical environments in porous $\mathrm{TiO}_{2}$ in photocurrent efficiency and degradation in dye sensitized solar cells," Journal of Physical Chemistry B, vol. 109, no. 48, pp. 22876-22883, 2005.

[50] T. Dittrich, B. Neumann, and H. Tributsch, "Sensitization via reversibly inducible $\mathrm{Ru}\left(\mathrm{dcbpyH}_{2}\right)_{2}(\mathrm{NCS})_{2}-\mathrm{TiO}_{2}$ chargetransfer complex," Journal of Physical Chemistry C, vol. 111, no. 5, pp. 2265-2269, 2007.

[51] H. Tributsch, "Dye sensitization solar cells: a critical assessment of the learning curve," Coordination Chemistry Reviews, vol. 248, no. 13-14, pp. 1511-1530, 2004.

[52] J. B. Asbury, Y.-Q. Wang, E. Hao, H. N. Ghosh, and T. Lian, "Evidences of hot excited state electron injection from sensitizer molecules to $\mathrm{TiO}_{2}$ nanocrystalline thin films," Research on Chemical Intermediates, vol. 27, no. 4-5, pp. 393406, 2001. 


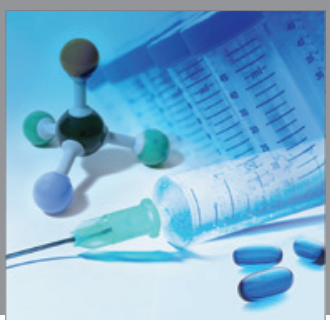

International Journal of

Medicinal Chemistry

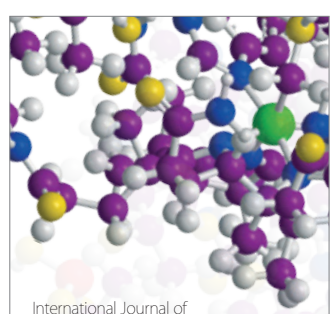

Carbohydrate Chemistry

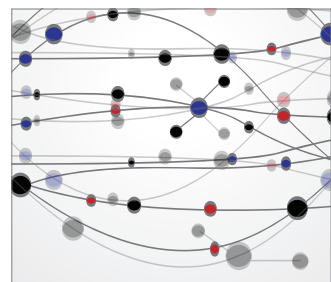

The Scientific World Journal
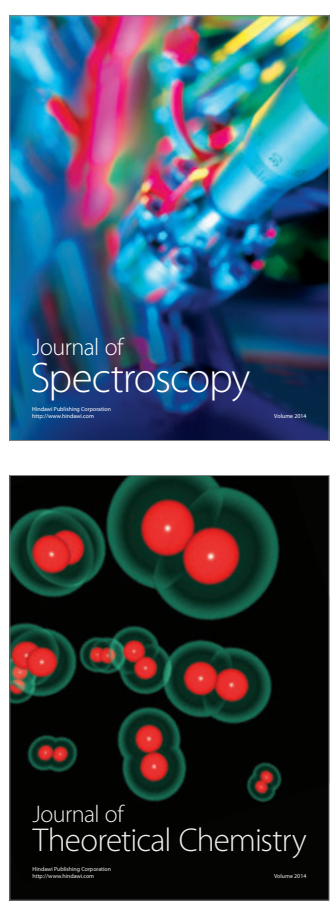
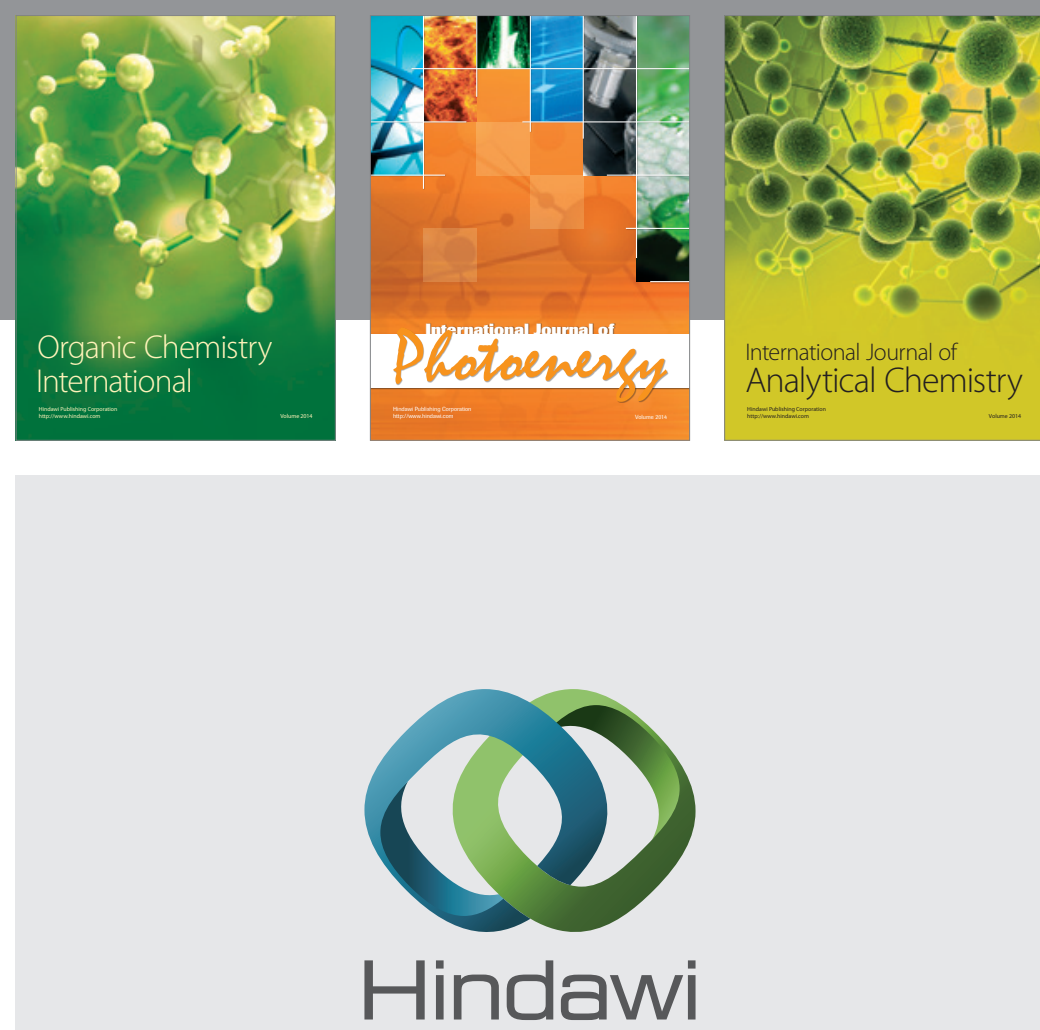

Submit your manuscripts at

http://www.hindawi.com
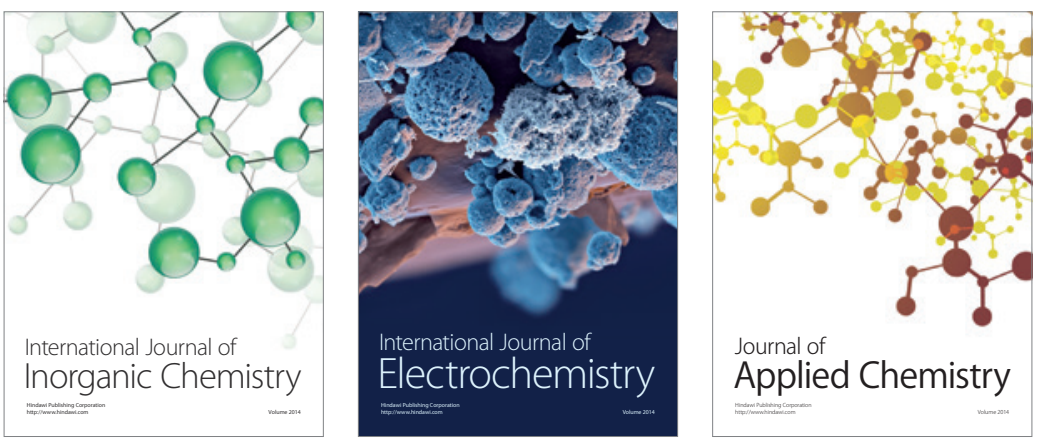

Journal of

Applied Chemistry
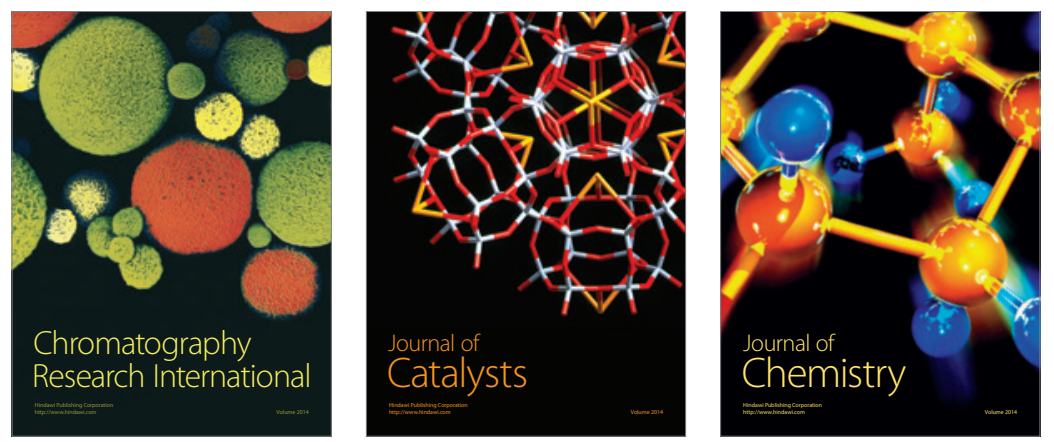
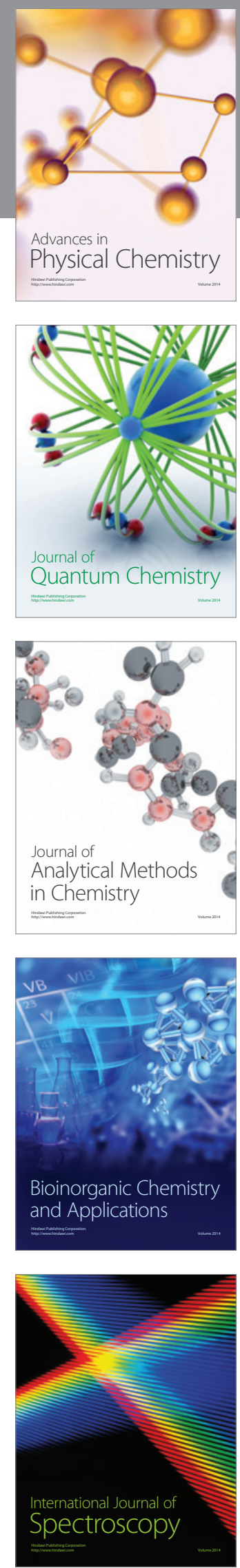